\title{
Good Practices of the European Union Countries Regarding the Integration of Refugees and Migrants
}

\author{
Desislava Argirova ${ }^{1}$ \\ 1 - Social and Legal Sciences, Technical University of Varna, Varna, Bulgaria \\ Corresponding author contact: desislavamp@gmail.com
}

\begin{abstract}
The countries of the European Union, which are final destinations or transit for refugees and migrants, face many social, humanitarian and financial challenges. They are expected to invest efforts and resources to enable migrant communities and the host society to activate their abilities, qualities and skills to build social cohesion and well-being between them. Local administrations provide many services that directly affect the integration of migrants and there-fore have a greater capacity to support the process of social cohesion, as opposed to governance at national level, which in many cases hinders local government initiatives to address social and economic problems arising from immigration. Integration is an extremely individual process and individual needs must be taken into account by the various institutions involved in this activity. Refugee integration is one of the indicators of democratic society, an indicator of the development and promotion of human rights and freedoms. It is a continuous and dynamic process that requires efforts and readiness on the part of refugees to adapt to their host society without having to give up their cultural identity, and therefore - readiness and understanding on the part of the host community and public institutions to perceive refugees as equal persons of themselves. Integration is a long-term two-way process of mutual adjustment of incoming immigrants and citizens of the host country.
\end{abstract}

Keywords: refugees, migrants, integration, European Union

\section{$1 \quad$ Introduction}

Asylum seekers are people who claim to be refugees but are not yet recognized as such. They apply for protection in the first country of the European Union (EU), in which they enter and receive refugee status or other form of international protection only after a positive decision by the national authorities. Refugees are people fleeing armed conflict or persecution. They are recognized as such in the host country on the basis of well-founded fears of persecution because of their race, religion, nationality, political opinion or belonging to a particular social group. Migrants, on the other hand, decide to relocate not because of a direct threat or persecution, but mainly to improve their lives, which can be expressed in finding a job, looking for better learning opportunities or reuniting with their families. Refugees are protected by international law, in particular the 1951 Convention relating to the Status of Refugees (1) and its Protocol (2), while national governments treat migrants according to their immigration laws and procedures. The level of experience on integration issues is different in the individual countries of the European Union. (21)

Integration is achieved through social inclusion and access to opportunities based on the principle of equality, namely access to education and training in the local language, employment, recognition of qualifications, health care, social assistance, housing and integration into social, cultural and civic life of society. The aim of the integration policy is to create economic, social, political and cultural preconditions for the integration into the host society of the recipients of international protection, in accordance with the basic general principles of the policy for integration of immigrants in the European Union. The task is to encourage the participation of those protected in the social, cultural and economic life of the municipalities. Integration policy can be effective if there is a constant dialogue between all actors in the reception, adaptation and cultural orientation phases of refugees and migrants, as well as in the provision of basic social and community services. It is also extremely important to build a network for 
cooperation and operational interaction between the widest possible range of participants, including state institutions, representatives of local self-government bodies and the non-governmental sector, as well as representatives of the refugee and migrant communities. (Bulgarian Red Cross, 2017)

\section{Good integration practices in the Republic of Bulgaria}

The legal framework for the integration of foreigners granted asylum or international protection in the Republic of Bulgaria is established in the Asylum and Refugees Act (3) and in the Ordinance on the terms and conditions for concluding, implementing and terminating an agreement for integration of foreigners granted asylum or international protection (5). The ordinance regulates the rights and obligations of the participants with a view to conducting the integration process, as well as the ways, terms and procedures for their implementation. The ordinance applies to persons with asylum, refugee or humanitarian status on the territory of Bulgaria, persons who have received international protection after relocation from another EU Member State and persons resettled from third countries.

Politics, considered as a type of social activity, is determined by the degree of development of society and the social relations between the people in it. Society is built on the basis of interaction between people and social ties between them. Civil society, in addition to being the environment in which the economic, social and cultural activities of people develop, is also the sphere of amateur activity of people of various kinds - political and religious associations, called to express and defend existing individual and group interests. (Petrov, T., 1993)

As early as the mid-1990s, a zone for social contacts and activities was established in the only then registered Registration and Reception Center at the State Agency for Refugees (SAR) under the Council of Ministers for applicants for international protection in the Ovcha Kupel district. Although initially it was only a place to overcome the isolation of women living in the center seeking international protection, it later acquired the status of an Integration Center (the Center) with a specific structure, agenda and programs. The activities in the center are provided financially and administratively by SAR, which also acquires licenses for vocational training. The Center starts to hold daily courses in Bulgarian language, led by specialists in teaching Bulgarian as a foreign language, courses in hairdressing, cosmetics, fashion design and computer work.

Residents of the Center, who until then were experiencing financial and communication difficulties, now receive free language training, procedures related to hairdressing and beauty services provided by the more advanced in the profession, sewing and repairing clothes, making knitting and jewelry by themselves. In this way, the residents have the opportunity to orient themselves to certain professions and to support their daily lives. For the mothers with small children in the center are provided playrooms for children, in which trained professionals deal with them, organize them into age groups, all together playing, singing, painting and making art objects. The activities related to the social adaptation and orientation of asylum seekers also include volunteers from non-governmental organizations, excursions and visits to historical sites in the capital and the country, as well as children's camps aimed at supporting the study of the Bulgarian language.

Bulgaria is one of the first countries in Europe to adopt a refugee integration program back in 2005, which started as an initiative of no more than 100 people a year, run by a single institution, namely the State Agency for Refugees. In 2013, when the number of asylum seekers increased significantly, the Bulgarian government adopted a new, decentralized integration model, delegating specific responsibilities to various institutions. The legal instrument allowing the integration of refugees to be carried out with the participation of local authorities and regional structures of a number of state institutions is the adopted Ordinance on the terms and conditions for concluding, implementing and terminating an integration agreement, which assigns municipalities the important responsibility to support and accompany the integration process. Support includes the provision of housing, language courses, employment opportunities, education, financial support, healthcare and all other elements leading to successful integration.

In the period 2005 - 2013 in Bulgaria are implemented the three three-year National Refugee Integration Programs (NRIP), which are an example of good practice applied in the capital of our country. The programs are prepared after an in-depth analysis of the legal framework and practice, they contain the basic principles and means for achieving the integration of refugees in Bulgaria. The adaptation and 
integration activities are aimed at creating conditions for the full realization of those who have received protection, providing an opportunity to develop their potential, as well as their active involvement in the economic, social and cultural life of Bulgarian society. The main goal of the measures is for the newly recognized refugees to integrate in Bulgaria for a period of up to one year, learning Bulgarian, learning a profession, getting acquainted with the state system, institutions, culture and life, gaining access to the labor market and moving to full self-sufficiency. the country.

The programs are centrally funded by the state budget, and are provided for approximately 100 people per year, of which 60 adults and 40 children. Among the activities financed by the NRIP are housing, Bulgarian language training, health insurance, vocational training and retraining, as well as child care. Although in this period the average number of beneficiaries of international protection is about 250 each year, in none of the years did the number of people willing to participate reach the planned 100, as most of the beneficiaries settled on their own or left the country, and a large number of those enrolled in the programs leave them prematurely, as they feel that they have already gained the confidence to take care of their own interests. The integration programs are monitored by the Integration Commission, which approves the individual integration plans and proposes to the Chairman of SAR termination of contracts with persons who do not comply with the requirements of the integration contract.

The Bulgarian language and vocational training courses are organized by SAR in cooperation with the Ministry of Education and Science and the Ministry of Labor and Social Policy. Active partners in the process of refugee integration are the Bulgarian Red Cross, the UN High Commissioner for Refugees and non-governmental organizations. The integration program is provided financially through the SAR budget. It also includes: a package of measures for the integration of newly recognized refugees; elaboration of a directory with information on the rights and obligations of refugees in Bulgaria, the powers and functional competence of state institutions and non-governmental organizations working with refugees; provision of housing services for refugees - information, assistance with administrative formalities, address registration, legal assistance and consultations; inclusion of refugees in employment and craft training programs at the labor offices and the National Chamber of Crafts, as well as their training for the development and implementation of small business projects; normative regulation of the access of adult refugees without education to the state educational system; inclusion of social mediators in the activities for social assistance to refugees; inclusion of refugees in national programs for health prevention and disease prevention; inclusion of refugees with special needs in various forms of psychosocial work, medical care, social patronage and cultural activities, etc.

Those wishing to join the NRIP submit an application within a certain period of time after receiving the relevant protection - refugee status or humanitarian status. A social worker from SAR conducts an interview with them, on the basis of which an individual integration plan is prepared. The individual integration plan includes specific measures for integration of the person and his family and deadlines for their implementation. The applications and plans are considered by an Integration Commission appointed by the Chairman of SAR, which in addition to employees of the agency includes representatives of NGOs, UNHCR, other institutions involved in the integration of beneficiaries in the Republic of Bulgaria. After a positive decision of the Integration Commission for inclusion of a person or family in the program, an Integration Agreement is concluded between him and the Chairman of SAR, which sets out the rights and obligations of both parties.

The activities related to the housing of the persons included in the NRIP are most often carried out through the mediation of the mediators, concluding a contract with the landlord, a copy of which remains in the personal file of the refugee. The integration commission, monitoring the implementation of the integration plan, determines the amount of the rent, which is financed under the NRIP. The health insurance activities envisage that the persons are insured from the budget of the program for the entire term of participation in it, and those for social assistance - upon entering the program each household receives one-time targeted assistance up to the amount specified for the year in the Implementing Regulations of the Social Assistance Act to cover basic needs and provide basic necessities. In connection with the activities for the care of the children, the persons are assisted in enrolling the children in kinder garden and the preschool groups, as the budget of the program pays the fees for kinder garden, as well as the amounts provided for the Bulgarian children, for one-time assistance in enrolling in first grade. Particular attention is paid to the school integration of children whose parents are included in the NRIP. Meetings are held with teachers and parents in order to prevent early dropping out of children and increase the conditions for their successful adaptation. Periodic consultations are held on the rights of 
refugee children, including unaccompanied minors. The refugee parents get acquainted with the Bulgarian culture and education. A lot of work is being done on their social inclusion in the Bulgarian environment by organizing intercultural activities with the participation of refugee children and their parents, together with Bulgarian children and their families. Particular attention is paid to research and development of curricula and projects related to the education of refugee children in Bulgarian schools.

Regarding Bulgarian language training, courses are held at the Integration Center of the State Agency for Refugees (SAR), using textbooks developed by Caritas - Bulgaria specifically for the needs of applicants and protected for level A1 and A2 under the Common European Framework of Reference for Languages, and for each day of attendance in the Bulgarian language course the participants are paid a daily scholarship, in accordance with the amounts provided in the Employment Promotion Plan for the respective year. The course lasts 6 months and the participants receive a certificate of proficiency in Bulgarian. In connection with the activities for Professional Qualification and Retraining, the SAR Integration Center conducts courses in several professions, and the participants are paid a daily scholarship in accordance with the amounts provided in the Employment Promotion Plan for the respective year. After passing the exam, participants receive a certificate of proficiency in the respective profession. For the purpose of more successful labor integration, the refugees who have undergone training courses under the Program, with the assistance of social experts from SAR or mediators from non-governmental organizations, are registered as active job seekers in the Labor Office Directorate. The main goal in ensuring employment for refugees is for them to gain access to the labor market, as well as to remain permanently in it. The highest percentage of employment of refugees is registered in the field of catering, car repair, construction and utilities. In 2014 the integration center of SAR at the Council of Ministers was closed with a change in the Structural Rules of the institution.

In April 2016, the implementation of a mini-pilot integration program for 40 people who received international protection in Bulgaria, funded by UNHCR and implemented by the Bulgarian Red Cross, began. The main activities set in the project are Bulgarian language courses level A1 and A2, vocational training, translation and legalization of documents, providing additional Bulgarian language lessons for children enrolled in school, as well as payment and enrollment in kinder gardens and nurseries, or payment for an hourly daycare for small children while their parents are taking a Bulgarian language course.

Participants are provided with a public transport card, study aids, and coverage of health insurance costs. Social workers are responsible for the organization, implementation and monitoring of integration measures, support the beneficiaries in their social and cultural adaptation, as well as assist them in their professional realization. (Bulgarian Red Cross, 2017)

Good practice in the field of integration is working with social mediators. Social mediators assisting asylum seekers and beneficiaries are selected from among migrants, asylum seekers, family members from mixed marriages, foreigners with authorized residence in the country, Bulgarian citizens who speak the most commonly used languages by asylum seekers, and who are familiar with the culture of the countries from which the largest groups applying for refugee and humanitarian status come. Social mediators play an extremely important role in the cultural orientation and integration of newcomers in the country. They are indispensable advisers and consultants in the first integration steps of asylum seekers. The mediators acquaint the asylum seekers with their rights and obligations, assist them in their daily activities, such as visiting the store, using public transport, banking and others. Assist them in medical services related to accompaniment and translation during a visit to a health institution, in contact with medical staff, for administrative services for the establishment of chronic diseases and disabilities, in the care of pregnant women, young mothers and children, awareness campaigns related to prevention of severe diseases and immunizations of children and others. Mediators also mediate contacts with individual institutions in issuing and legalizing documents, registering, assisting in the enrollment of children in kinder garden and school, and assisting parents in contacts with school authorities and teachers. Social mediation activities are funded by programs and projects for certain periods of time.

The UNHCR-funded Bulgarian Red Cross Refugee Integration Program, in turn, includes activities to support the social and economic integration of asylum seekers by providing advice on issues related to life and rights in Bulgaria. access to medical care and services, assistance in finding a job. This program helps for social and cultural orientation of this group of people, supports their housing for a period of three months, supports the education of children studying in Bulgarian schools through additional training in Bulgarian, provides textbooks and teaching materials. It also supports refugees with special needs, including the disabled, single parents, adults and separated children. 
Another program that helps to promote the communication of beneficiaries of international protection with the local population and thus facilitates their integration into Bulgarian society is the Mentoring Program implemented by the Center for Integration of Refugees and Migrants "St. Anna" to Caritas Sofia. It has existed since 2016, as a proven and working practice in helping people who have received international protection living in Sofia. Faced with a completely new and unfamiliar environment, far from home, people who have received international protection need someone to help them navigate the situation - a friend and partner with whom to share issues that concern them, to exercise Bulgarian language and spend time in the company of a local person. When couples are formed, their personal interests and talents are taken into account. The mentoring couple usually sees each other at least once a week and exchanges skills and knowledge, building a lasting friendship. Mentors go through preliminary training, in which they learn more about the nature of mentoring, effective communication, the goals of the program, how to teach Bulgarian through conversation and involvement in appropriate cultural events. Volunteers who act as mentors are motivated people driven by a desire to do good. People who want to lay the foundations of their new life in Bulgaria, in turn, are motivated to learn more about the culture, way of life and customs of the country in which they want to build their new home. Caritas mentoring program helps these two groups of people to make their dreams come true by building a bridge to their worlds, hopes and desires and showing their best by erasing prejudices and fears. (Sacab, A., 2017)

Education - and in particular that of children, is the most successful integration sector, which is a result of legislative amendments prepared and adopted by the Ministry of Education and Science (MES) in 2017, the consistent implementation of new policies by of the regional departments of education, as well as the dedicated field work of principals and teachers, which has already given hundreds of children a chance to learn to read and write in Bulgarian. The big positive change occurred in April 2017 with the approval of a special ordinance introducing a simplified procedure for enrollment of applicants for and protection in school, namely Ordinance 3 on the terms and conditions for admission and training of persons seeking and receiving international protection (6) If before enrollment of children diplomas from the countries of origin and a document from SAR are required for completed three-month course in Bulgarian language (which the Agency stops organizing at the end of 2013), after the entry into force of the Ordinance these conditions drop out. Instead, an application for a child to be enrolled in a school is submitted to the relevant Regional Department of Education (RDE), which issues an order for admission of the student to a specific school. A special commission set up by the principal of the particular school, which usually includes a possible future class teacher, subject teachers, a psychologist, and often the principal himself, determines which class the child should enter after talking to him. According to the Ordinance, up to the fourth grade the enrollment is done according to the age of the student, and in the upper grades - at the discretion of the commission, as the child cannot be returned more than three grades later than the one corresponding to his age. Ordinance 3 allows all students to study to enter a school, even if they do not have diplomas from their country of origin.

For children who have such documents, the more general Ordinance 11 (7) on the assessment of student learning outcomes is in force, according to which diplomas for children up to sixth grade are recognized on the spot by the principal of the particular school and the big ones - from RDE. The legislative changes that became possible in the context of the adoption of the new Law on Preschool and School Education (4), and in particular in its Art. 9, para 2, item 3, which regulates the right to free education and training of children seeking and receiving protection in Bulgaria at compulsory school age, leads to a six times increase in the percentage of coverage of children in the educational system. In the school year 2016/2017 it is about 10\% - 119 children out of a total of 1319 in compulsory school age, accommodated in SAR centers as of 19.10.2016, and in the next - 2017/2018 the percentage becomes 60\% - 189 of 338 in SAR. These data remain stable in 2018/2019 and 2019/2020, thus better coverage of children becomes an established and field practice. Unlike previous years, the data show that for 2019/2020 almost all children accommodated in SAR centers are already students. (see Figures 1,2,3). Out of 104 children, 65 boys and 39 girls, 87 are students and 7 are in a preschool group. The largest number of children is from Iraq (46), followed by those from Syria (45), Iran (6), Afghanistan (5), Pakistan (1) and Nigeria (1). Potential students who remain outside the education system are mainly unaccompanied children or those whose parents do not know how, cannot or do not want to enroll their children in school. Some of the refugee children are educated in all three private Arab schools in Sofia - Iraqi, Lebanese and Palestinian, which are not part of the Bulgarian educational system, and students 
who have graduated from these schools must recognize the diplomas received under Ordinance 11 for assessment of student learning outcomes.

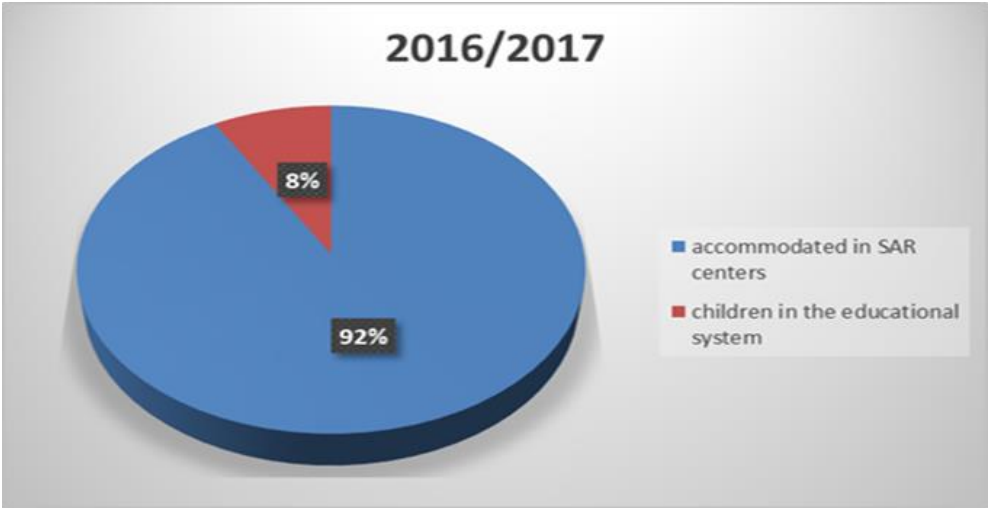

Fig. 1. Children integrated into the education system in relation to the total number of children accommodated in SAR centers in 2016/2017

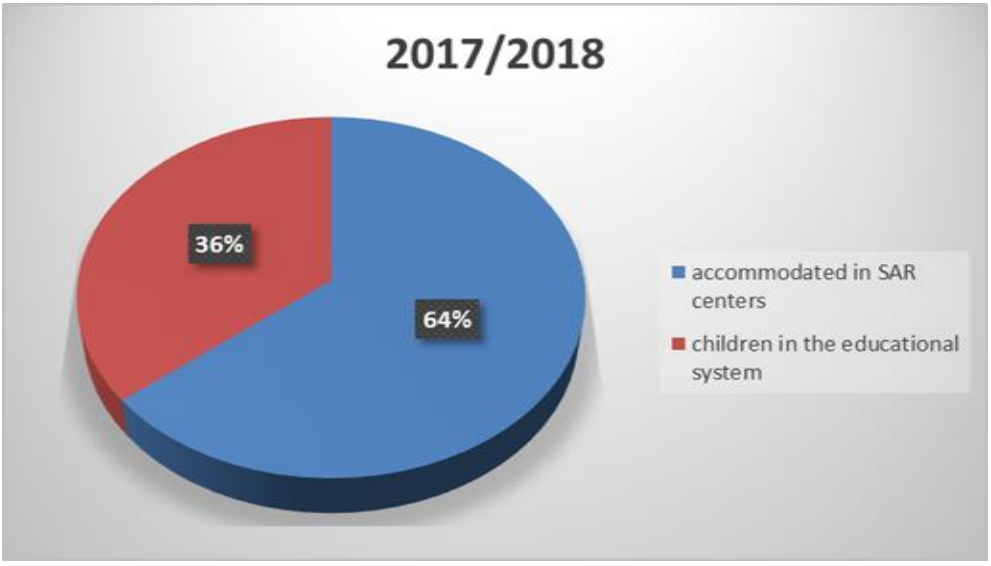

Fig. 2. Children integrated into the education system in relation to the total number of children accommodated in SAR centers in 2017/2018

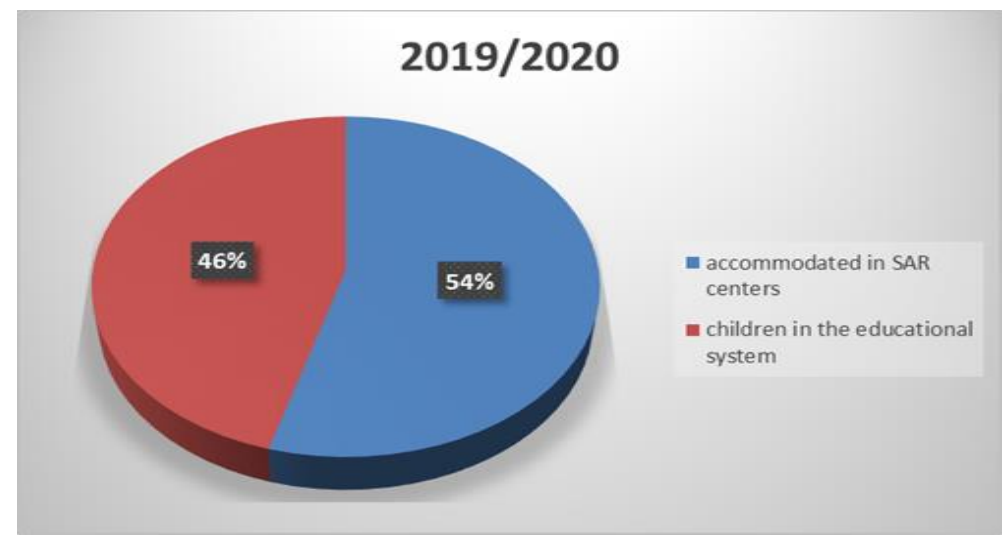

Fig. 3. Children integrated into the education system in relation to the total number of children accommodated in SAR centers in 2019/2020

Unhindered access to education is often cited by refugee families who remain living in Bulgaria as one of the main motives behind their decision. The feedback from the school administrations and pedagogues themselves is almost always very positive: children, especially the younger ones, quickly 
learn Bulgarian, often become translators for their parents and do not encounter problems in adapting to the Bulgarian school environment. Many teachers admire the attitude towards the educational institution and the figure of the teacher, which is deeply respected, as is the tradition in the countries of origin. In addition, teachers working with refugee children across the country have the chance to upgrade their pedagogical skills in a series of trainings organized by UNHCR and the MES each year: they receive advice and guidance on how to teach Bulgarian as a foreign language, what are the cultural specifics of countries of origin, what is the procedure for international protection in Bulgaria, etc. Some teachers also have the chance to visit their colleagues in Western Europe.

\section{Good integration practices in other Member States of the European Union}

For the protection of refugees, a unified international and European legal framework has been established, the existence of which presupposes the existence of similar administrative structures in the different countries, related to the implementation of the policies on the problems of refugees. There are similarities in the functioning administrative structures, as well as similarities in the model of refugeerelated policies, despite the specifics of individual countries. In the EU Member States, the policies applied to refugees and their integration into society aim at their social inclusion in the local community and overcoming social exclusion. Recipients of protection should preserve their cultural identity and at the same time embrace the values of the host community.

Finding housing and the possibility of accommodation after receiving international protection is the first major problem that these people face in the new country. Refugee reception centers and asylum seekers are only a temporary mechanism of state housing policy, which cannot solve the need to find housing in the long run.

In addition to finding housing, employment and education opportunities are paramount for people who have been granted asylum in another country. Moreover, a number of studies among immigrant communities confirm that beneficiaries of international protection are also among the most active immigrants due to the desire of these people to restore the standard of living they have lost in their homeland.

Refugee integration policies are implemented on the basis of strategic documents adopted by the relevant state or local authorities. These documents, namely the integration strategy and the integration plan, contain the main guidelines and measures for the implementation of the integration policies. Measures are envisaged mainly in the following areas, which are directly related to the integration of refugees in the local community: finding housing and accommodation opportunities; employment and education; healthcare; specific measures for social inclusion and access to rights.

The integration measures are implemented on the basis of an official document between the refugees and the state, as well as municipal authorities, namely on the basis of an integration contract. The treaty formalizes the mutual commitments between each legally arrived immigrant and the relevant receiving authorities through its binding nature. Newly arrived foreigners have certain obligations in order to successfully integrate them into society, and they can be: learning the relevant local language, passing mandatory courses in civic education and mandatory assessment of professional skills, and competencies of refugees.

The integration measures are implemented primarily on the basis of the existing public-private partnerships between the state, the municipality and the various subjects of the civil society. The most frequent partners of the municipal authorities are the existing civil society organizations, which directly implement the integration policies. The role of the state and municipal authorities is to support and coordinate the activities of non-governmental organizations, creating the conditions for the implementation of integration policies. (Eftimova, D., Lazarova, I., Lazarov, Q, Sofia, 2014)

The Republic of Croatia is largely a country of emigration and transit. The number of migrants and refugees in Croatia is relatively small, and integration policy is at an early stage of development and is largely regulated by the authorities at national level. Although many cultures collide in the city of Osijek, there is a tendency to deny multiculturalism, which in turn affects citizens' attitudes towards migrants and refugees. In Osijek, migrants participate in urban life through active secondary school education, extracurricular activities and sports, as well as interactions with volunteers organized by the Osijek Volunteer Center. The staff of the Center has extensive experience with asylum-seeking families, children, 
adults, the disabled and unaccompanied minors in reception centers. Volunteers help refugees and migrants in reception centers to spend their full time there through a variety of social activities aimed at early education and socialization of young children, primary education assistance, social relations in the community, support for women, cultural and social orientation and exchange, with the Center providing significant humanitarian assistance.

Volunteers are often organized in social assistance activities for unaccompanied minors accommodated in the Home for Children and Youth in Osijek, as well as for migrants and refugees at the Asylum Center in Kutina. The initiatives include sports activities, seminars, cooking and various types of social exchanges, involving all stakeholders - the Ministry of Interior, the Osijek Social Welfare Center, the Home for Children and Youth and the Red Cross. Volunteers have an important role to play in creating social links between young refugees and the local community, which greatly contribute to their successful integration. A large part of the population there, according to the study conducted in the report (Popov et al., 2018), strongly emphasizes that local communities and the media must be well prepared for the arrival of migrants. It is necessary to ensure a positive climate in order to avoid the risk of misinformation or of fake news provoking xenophobic attitudes and manifestations. The role of the media is particularly important and they should be encouraged to present positive stories about migrants and refugees, the interviewees said. For their part, local administrations need to actively communicate with third-country nationals to better understand their needs.

Prague is the cultural, political and economic center of the Czech Republic, and a key city in Central Europe. There live about 1.3 million people, of whom 200,000 are foreigners who came to the city for work, study or family reunification, making up $15 \%$ of the city's total population. Prague can be considered one of the western cosmopolitan cities, which has become a destination for many third-country nationals in the medium and long term. The City of Prague has set up a website specifically for foreigners living in the city (www.prahametropolevsech.eu), which helps them to obtain information on the basic services offered by various public institutions and to make communication with migrants and refugees more effective. Praguer mobile application, which offers practical information about life in Prague. The city has also created intercultural services, available through a city subsidy, to support residents who do not speak Czech and are not yet able to navigate the country. These and other services that help foreigners gain more independence are offered by the Center for Integration - Prague. To address the issue of language barriers for migrant children in schools, Prague supports student learning by choosing a school in each urban area that offers additional Czech language lessons for them, and a network of selected schools contributes to faster adaptation of students with different mother tongues to regular Czech classes. (Bulgarian Red Cross, 2017)

In Italy, the Ministry of the Interior is responsible for providing protection and immigration issues, in cooperation with the Ministry of Foreign Affairs and the Ministry of Labor and Social Policy. Local administrations are involved in the integration process by applying desk services for applications for work permits, family reunification, residence permits and language tests for proficiency in Italian. Since 2012, an integration agreement has been signed between the Italian state and migrants, including refugees. It includes the organization of Italian language, social and cultural orientation courses. The Municipality of Rome works with a non-governmental organization which provides information on beneficiaries of international protection, organizes Italian language training, individual consultations and educational activities. (Sacab, A. 2017) The Sprar protection system for asylum seekers and refugees has been introduced in Italy (https://www.Sprar.it/english). It provides for the implementation of specific individual programs aimed at supporting and protecting migrants and facilitating their economic and social integration. This system not only distributes food and housing services, but also provides material conditions for asylum seekers and refugees, including the supply of clothing, bed linen, pocket money, food, accommodation, language training, guidance and access to local services, vocational training, psychosocial, health and legal protection (Bulgarian Red Cross, 2017) In the city of Rubano, the integration of immigrants takes place mainly through their children, who speak Italian and can help their families to socialize. (Popov et al., 2018)

The integration agreement is concluded between the state and third-country nationals over the age of 16 who enter Italian territory for the first time. It aims to reaffirm the authorities' commitment to providing language and civic education that will enable foreigners to learn the language at a spoken level, to know the basic principles of the country's constitution, the organization and functioning of public institutions and the way of life in Italy. Through the Agreement, foreign nationals reaffirm their commitment 
to fulfill their obligations set out in the Charter of Values of Citizenship and Integration of the Italian Government, adopted in 2007 (17). An example of good practice in the field of social inclusion is the Integra Program. It is a social cooperative dealing with projects for the social inclusion of immigrants and refugees. The program is based in Rome and is managed by the Center for Immigration, Asylum and Social Integration, in agreement with the Metropolitan Directorate for Social Policy, Subsidiarity and Health. (20)

The Festival of Diversity is held in the city of Košice, Slovakia, which collects and tells, in the form of art, stories of people from different minorities and cultures. (https://vymenniky.sk/festival/festivalrozmanitost/) Through music, dance, theater, exhibitions, film screenings, art workshops and other art forms, the festival offers the opportunity to learn about new values and traditions, and the goal is to contribute to the understanding of differences and the increase of tolerance in society. (Bulgarian Red Cross, 2017) In Slovakia, refugees have been identified as a separate target group for employment services, and municipalities are involved in the employment process. The Slovak Humanitarian Council has signed contracts with various municipalities in Slovakia to provide services to recipients of subsidiary protection (humanitarian status) (Sacab, A., 2017).

According to the latest report of the Office for Foreigners and Borders (SEF), the number of foreign nationals residing in Portugal has increased by $22.9 \%$ compared to 2018. In 2019. there are 590,348 documented third-country nationals holding a residence permit, the highest since 1976. This figure represents 5.7\% of the total population living in Portugal. The report also highlights that 151,304 Brazilians represent approximately a quarter of the total number of foreigners in Portugal (25.6\%) and have a $45.5 \%$ increase over the previous year. The Cape Verdeans are the second largest community (6.3\%), while the British are the third (5.8\% of the total). As regards new residence permits, in 2019 the SEF issued 129,155 permits, of which $37.8 \%$ of residence permits were for Brazilian nationals, $6.5 \%$ for Britons and $6.1 \%$ for Italians. India (4.9\%) and Nepal (3.9\%) are in fourth and fifth place. In terms of integration, SEF has implemented a number of projects to unite and facilitate the connection of local and foreign citizens. For example, the SEF on the Move program, which targets vulnerable groups, the elderly and children, aims to promote the legalization of third-country nationals. The SEF Goes to School program has carried out activities to inform and legalize young irregular immigrants who are still attending school. The Aliens and Borders Service Portal (SEF) creates a private area - MySEF where services can be provided. These services include renewal of permits, online certificates, electronic payments, management of SEF interviews and data changes. SMART SEF ID is a pilot project that aims to facilitate the renewal of residence permits for students through the operational partnership between SEF and the University of Coimbra. The SEF Contact Center is a telephone platform that facilitates contacts between foreign nationals and the SEF, promoting the reception and integration of migrant communities. This service is provided in partnership with civil society organizations through the accommodation of trained socio-cultural mediators in several languages. (18)

In 2015 The local authorities of Barcelona, Spain are beginning to actively encourage all unregistered residents to register in the municipal register, and these measures are mainly aimed at migrants and refugees. Registration is the first and basic step in building trust in these groups of people, and the municipal register is an important tool for the sustainable development of Barcelona, providing reliable and up-to-date data on residents, thus supporting adequate service planning. By registering with the municipal center, refugees have access to all local services, including sports, public facilities, libraries, schools, free Spanish language training, emergency social services and healthcare. Measures planned and funded include free legal aid for refugees and migrants, and this set of services is provided through non-governmental organizations, which ensure the dissemination of useful information on specific procedures for accessing services, such as obtaining a health card and access to the health system. In partnership with the municipality and state institutions, NGOs provide advice on the recognition of qualifications and access to the labor market.

The municipal register, known as the Padron, allows all residents, regardless of their status, to have access to the healthcare system and to all local services provided by the region of Catalonia, and even residents who do not have a permanent address are also entitled to register. As a result of this initiative, in 2017. Barcelona has published a comprehensive action plan to improve the social situation of refugees and migrants in the city, with the first goal being to ensure universal access to municipal public services. At that time, a Center for Refugee and Migrant Services, including for asylum seekers, was set up in Barcelona. The services provided include free legal advice, social 
orientation in the city and emergency assistance, and a network of 120 public and non-profit organizations cooperates with the city authorities to provide information and services to refugees and migrants. (Bulgarian Council for Refugees and Migrants, 2019)

The main document governing refugee law in France is the Code of Entry and Stay of Aliens and the Right to Asylum, established in 2004. This law specifies the process that asylum seekers must go through, while allocating the responsibilities and functions of state institutions. Among them, the Office for Immigration and Integration is the body charged with competences and commitments regarding the integration process for all foreigners in France, including the refugee group. (15) As regards legal procedures specifically related to the assessment of refugee status or the need for subsidiary protection, competences are entrusted to the Office for the Protection of Refugees and Stateless Persons. (16) In France, there is an Office of Immigration and Integration at the Ministry of the Interior, consisting of 15 people: 8 civil servants, 5 experts, 2 administrative staff, working in cooperation with the administrativeterritorial units that implement national policies at local level. Integration support is provided for a period of 5 years. Since 2007, all migrants, including refugees, have been required to sign a reception and integration agreement. The contract provides for attending French language courses, assessment of professional skills and competencies, a course in social and cultural orientation. Recipients of international protection are allowed to stay in reception centers for up to 6 months. The Ministry of Housing, Territorial Equality and Agriculture implements a housing program implemented by housing associations, which act as intermediaries between private landlords and refugees. Refugees can stay in rented housing for 18 months. (Sacab, A., 2017)

A good example of housing policy for refugees in France are the programs that promote the system of so-called "Creeping rent". The purpose of this practice is to allow particularly vulnerable groups in society to become "subtenants" of apartments for a certain period of time until the entire rent is transferred to their name. The organizations implementing such programs practically bear part of the costs of these households until they build the necessary financial independence for themselves. (Eftimova, D. \& Lazarova, I. \& Lazarov, Q., 2014)

In Austria, the Ministry of the Interior is responsible for immigration and administers integration programs. The Ministry of European Affairs, Integration and Foreign Affairs monitors some of the integration programs administered by the Ministry of Interior. The Ministry of Labor, Social Affairs and Consumer Protection is responsible for employing migrants and refugees. Integration activities are within the competence of local authorities. Since 2011, all migrants have been required to sign an integration agreement. It includes the opportunity for German language training, help with finding a job, help with enrolling children in school, providing information, as well as social orientation. Municipalities provide vouchers for German language courses. Information sessions are held in public places, such as parks, squares, shopping malls, for local people on topics related to migration, integration and diversity. The City of Vienna has opened a forum for civil society organizations, the private sector and political representatives. Municipal authorities cooperate with non-governmental organizations, which provide information to beneficiaries of international protection, offer German language courses, individual consultations and other educational activities. (Sacab, A., 2017)

The House for Integration was established in 1995 and is recognized by the Vienna administration, and at the state level, as a good example of an initiative working in the field of reception and integration of asylum seekers who have received subsidiary protection and refugee status. as well as immigrants. A special target group of the House for Integration are vulnerable people - traumatized, unaccompanied minors, people with mental or severe physical disabilities, single parents, pregnant women, etc. who need special help due to their specific needs. The activities for integration of the people in the House are focused on two main areas. The first is related to counseling and assistance, as the team of the House includes specialists in the field of psychological, social and legal services. The second is related to education and cultural activities, including training to acquire skills for the realization of the labor market, learning foreign languages and caring for children.

In Poland, the integration policy is most pronounced in the accommodation of protected persons in municipal housing. In the city of Warsaw, five municipal apartments are provided only to refugees and persons granted humanitarian status. In the city of Lublin, Caritas - Poland has a long-term partnership with the Municipal Social Service. There is an interdisciplinary team of refugee integration experts working to revise local legislation on the provision of housing, services and assistance to beneficiaries of international protection in Lublin. The expert team has been able to bring about changes in local 
legislation that allow persons with refugee and humanitarian status to apply for housing that is municipal property.

In Denmark, municipalities are responsible for receiving resettled refugees and take care of finding suitable shelter for them. Relocation to another municipality within the first three years of the integration period is only possible if the host municipality assumes responsibility for the costs and implementation of the adaptation and integration program. This usually happens if the refugees have found a job or an opportunity to continue their education in the respective municipality. The integration program offers three years of Danish language training without other commitments. Language schools are run by municipalities or other contractors, such as the Danish Refugee Council. The social workers from the municipality and to a lesser extent the representatives of the civil society assist the refugees in the preparation of an individual contract or action plan, which is concluded between the municipality and the refugee on the basis of an assessment of his specific skills and qualification. The aim is to facilitate a person's access to the Danish labor market or to some form of education. The integration program can also focus on vocational training. Contracts are monitored periodically. Denmark has a well-established network of volunteer organizations that help integrate resettled refugees. The Danish Refugee Council, the Danish Red Cross and other non-governmental organizations support the process of refugee integration. These organizations reach the municipalities through a nationwide network of thousands of volunteers, and can also be partners of the municipalities in the implementation of the mandatory integration program. NGOs help in the integration process by providing various services, such as establishing contacts or a network for interaction between families, providing courses in cultural and civic orientation, as well as language courses. They organize seminars for students, joint dinners, summer camps and activities for young people, assist in finding work and places for vocational training.

In order to encourage municipalities to accept refugees for resettlement, municipal authorities in Finland receive financial resources for the implementation of the integration program. The municipality is paid a lump sum for each refugee to cover the costs of integration during the first three years. Once the refugees arrived in the municipality, Finnish Red Cross volunteers assisted them in settling into their new homes, introducing them to practical details of everyday life. This includes the location of shops, schools, municipal buildings, health centers and how to use public transport. Municipalities provide housing for resettled refugees, and during the three-year integration program, refugees are entitled to financial assistance and rent payments for housing. (Sacab, A., 2017)

The German federal government determines the policies that are implemented by the federal states. The Federal Office for Migration and Refugees is responsible for immigration, integration and asylum. The Federal Ministry of Labor and Social Affairs is responsible for employing migrants and refugees.

Mothers of the Neighborhood is a project that began in 2004 in Berlin as an initiative of local people. Subsequently, their activities were supported by a number of local and regional institutions. Its purpose is to disseminate information and services to help families with young children. Immigrant and Germanspeaking mothers in the neighborhood undergo training before being sent to meet newly arrived, often isolated families. These newcomers are encouraged to visit other informal women's groups or use local daycare centers. The fact that advice is provided by women of similar backgrounds and family backgrounds helps build mutual trust and gives newcomers the confidence to ask questions, seek answers and accept change more easily. With their knowledge of the challenges faced by newly arrived immigrants, including refugees, neighborhood mothers are community mediators and provide valuable assistance to immigrant families in need of community services, support for school-age children, or assistance with learning German (19)

\section{Conclusion}

The quality of integration policies in each country is an indicator of the public's ability to counter racism and discrimination, but it is also an indicator of the ability of minority and immigrant groups to adapt to the country's existing rules, regulations and public order. which they wish to be. (Eftimova, D. \& Lazarova, I. \& Lazarov, Q., 2014)

The integration approach of EU countries should include key elements such as support for local language learning, information and counseling services, legal advice and guidance, as well as 
administrative support in issuing the necessary documents, permits and in providing housing. Successful integration implies access to the labor market, education, vocational training, ensuring a safe and nondiscriminatory urban environment, and ensuring that migrant children have access to education. Social work with refugees and, above all, emotional support from social workers and educators support the process of socialization and integration of these people in the host society, while preserving their cultural identity.

Integration means creating a favorable environment for the active inclusion of migrants in the social, economic and political spheres. The development of communication channels to promote the contribution of migrants and refugees to society, the promotion of positive examples and models for good integration through broad public information, together with cooperation between city authorities, NGOs and various institutions, are a prerequisite for ensuring successful integration practices. From the point of view of the Delphi method, integration can be understood as a relatively short peri-od of time set aside for the study, in which certain tasks planned in advance in the research process are solved, in which the opinions of experts converge. (Petrov, T., 2019)

Most municipalities must maintain databases with accurate statistics on third-country nationals, broken down by country of origin, age, education, professional skills, etc. Better coordination between levels of government is needed, giving more powers to local administrations. Following the example of the city of Prague, Czech Republic, cities should be encouraged to develop an online portal or resource websites to simplify the flow of information to foreign nationals. In this process, cities can collaborate with IT companies, employers, NGOs, hospitals, universities and others. As the integration process is multifaceted, municipalities must work in cooperation with all stakeholders, including relevant national authorities such as ministries, agencies, employers and enterprises, schools, NGOs and others, to meet national standards and integration priorities; and to use scarce resources more efficiently. Capacity building of the municipal administration for the successful implementation of political commitments should be a key line of action for cities, and the exchange of good practices and learning from other European cities will increase the knowledge and motivation of local authorities in individual EU countries. (Popov et al. 2018)

\section{Acknowledgment}

This report has been developed in connection with project PD1/2020 of Technical University of Varna in aid of $\mathrm{PhD}$ students on the topic of the project "Social protection and integration of refugees" (comparative analysis)

\section{References}

Convention relating to the Status of Refugees (Geneva Convention). adopted on 28 July 1951 and promulgated in the State Gazette, no. 88 of 15 October 1993 Retrieved from: http://refugees.farbg.eu/sbornik-po-bejansko-pravo/normativni-dokumenti/jenevska-konvencia

Protocol relating to the Status of Refugees, adopted on 31 January 1967, in force for Bulgaria since 12 May 1993. Retrieved from: http://refugees.farbg.eu/sbornik-po-bejansko-pravo/normativnidokumenti/protokol-za-statuta-na-bezhantsite/

Law on Asylum and Refugees, in force since 01.12.2002, amended. and ext. S.G.. issue 89 of October $16,2020$.

Law on Preschool and School Education, Promulgated, SG, iss. 79 from 13.10.2015, in force from 18.07.2017

The Ordinance on the terms and conditions for concluding, implementing and terminating an agreement for integration of foreigners with granted asylum or international protection, SG, issue 65 of 19.08.2016, in force since 19.08.2016, Retrieved from: https://dv.parliament.bg/DVWeb/showMaterialDV.jsp?idMat=116399 
Ordinance № 3 of 06.04.2017 on the terms and conditions for admission and training of persons seeking or receiving international protection Prom. - SG, no. 32 from 21.04.2017, in force from 21.04.2017

Ordinance № 11 of 01.09.2016 for evaluation of the results of the students' education Prom. - SG, no. 74 of 20.09.2016, in force since 20.09.2016; ed. and add., no. 78 from 29.09.2017

Bulgarian Red Cross. (2017). Handbook for Integration of Asylum Seekers or International Protection in Municipalities.

Bulgarian Council for Refugees and Migrants. Good Practices for Integration of Refugees from Municipalities in Europe. Retrieved from: https://bcrm-bg.org/wpcontent/uploads/2019/11/2019_Good_practices_printable-1.pdf

Eftimova, D., Lazarova, I., \& Lazarov, Y. (2014). Social integration of refugees - good practices and local policies in five European capitals. Institute for Public Environment Development

Popov, S., Filipova, P., \& Gabova, S. (2018) Comparative City Audit Report. ISBN 978-619-91126-70

Sakab, A. (2017). Is there a desire, is there a way. Private sector involvement in the employment of beneficiaries of international protection, UNHCR Bulgaria. Retrieved from: https://www.unhcr.org/bg/wp-content/uploads/sites/18/2016/12/Employment-for-RefugeesFINAL-BG.pdf

Petrov, T. (1993). Introduction to political science (Vavedenie v politologiata). Varna. ISBN - 954-799260-0

Petrov, T. (2019). Using the Delphi method to analyze the economic efficiency of social services (Izpolzvane na metoda Delfi za analiz na ikonomicheskata efektivnost na socialnite uslugi), Proceedings Third Scientific and Practical Conference with International Participation, Social Work, Management and Social Development: Contemporary Challenges, Perspectives and Innovative Practices. Technical University of Varna, 10-11.10.2019. Varna, ISBN 978-954-200803-3

Official website of the Office for Immigration and Integration of the Ministry of the Interior of the French Republic. Republican Treaty of Integration. Retrieved from: http://www.ofii.fr/lecontrat-d-integration-republicaine

Official website of the French Office for the Protection of Refugees and Stateless Persons. www.ofpra.gouv.fr

Page of the Italian Ministry of the Interior, Information on the integration agreement, https://www1.interno.gov.it/mininterno/export/sites/default/it/sezioni/sala_stampa/speciali/accordo_integrazione/index.html

European web site on integration. Migrant Integration Information and good practices, Portugal: Remarkable growth of foreign citizens living in the country. Retrieved from: https://ec.europa.eu/migrant-integration/news/portugal-remarkable-growth-of-foreign-citizens-living-inthe-country

Integration Facilitators program for disadvantaged neighborhoods in Berlin. Retrieved from: https://use.metropolis.org/case-studies/integration-facilitators 
European Union. The situation of migrants and refugees in Europe. European Youth Portal Retrieved from: https://europa.eu/youth/get-involved/your\%20rights\%20and\%20inclusion/situation-migrants-and-refugees-europe_en 